\title{
Tumor-Associated Epilepsy in Patients With Brain Metastases: Necrosis-to-Tumor Ratio Forecasts Postoperative Seizure Freedom
}

\section{Majd Bahna ( $\sim$ majd.bahna@ukbonn.de)}

University Hospital Bonn: Universitatsklinikum Bonn https://orcid.org/0000-0001-6766-7721

\section{Muriel Heimann}

University Hospital Bonn: Universitatsklinikum Bonn

\section{Christian Bode}

University Hospital Bonn

\section{Valeri Borger}

University Hospital Bonn: Universitatsklinikum Bonn

\section{Lars Eichhorn}

University Hospital Bonn

\section{Erdem Güresir}

University Hospital Bonn: Universitatsklinikum Bonn

\section{Motaz Hamed}

University Hospital Bonn: Universitatsklinikum Bonn

\section{Ulrich Herrlinger}

University Hospital Bonn

Yon-Dschun Ko

Johanniter Hospital Bonn

Felix Lehmann

University Hospital Bonn

\section{Anna-Laura Potthoff}

University Hospital Bonn: Universitatsklinikum Bonn

\section{Alexander Radbruch}

University Hospital Bonn

\section{Christina Schaub}

University Hospital Bonn

\section{Rainer Surges}

University Hospital Bonn

Johannes Weller

University Hospital Bonn

Hartmut Vatter 
University Hospital Bonn: Universitatsklinikum Bonn

\section{Niklas Schäfer}

University Hospital Bonn

\section{Matthias Schneider}

University Hospital Bonn: Universitatsklinikum Bonn

\section{Patrick Schuss}

University Hospital Bonn: Universitatsklinikum Bonn

\section{Research Article}

Keywords: epilepsy, brain metastases, cancer, seizure freedom, ILAE

Posted Date: February 25th, 2021

DOl: https://doi.org/10.21203/rs.3.rs-241560/v1

License: (1) This work is licensed under a Creative Commons Attribution 4.0 International License. Read Full License

Version of Record: A version of this preprint was published at Neurosurgical Review on May 14th, 2021. See the published version at https://doi.org/10.1007/s10143-021-01560-y. 


\section{Abstract}

Surgical resection is highly effective in the treatment of tumor-related epilepsy (TRE) in patients with brain metastases (BM). Nevertheless, some patients suffer from postoperative persistent epilepsy which negatively impacts health-related quality of life. Therefore, early identification of patients with potentially unfavorable seizure outcome after BM resection is important. Patients with TRE that had undergone surgery for BM at the authors' institution between 2013 and 2018 and were analyzed with regard to preoperatively identifiable risk factors for unfavorable seizure outcome. Tumor tissue and tumor necrosis ratios were assessed volumetrically. According to the classification of the International League Against Epilepsy (ILAE), seizure outcome was categorized as favorable (ILAE 1) and unfavorable (ILAE 2 - 6) after 3 months in order to avoid potential interference with adjuvant cancer treatment.Among all 38 patients undergoing neurosurgical treatment for BM with concomitant TRE, 34 patients achieved a favorable seizure outcome (90\%). Unfavorable seizure outcome was significantly associated with larger tumor volumes $(p=0.012)$, a midline shift $>7 \mathrm{~mm}(p=0.025)$, and a necrosis/tumor volume ratio $>0.2$ $(p=0.047)$. The present study identifies preoperatively collectable risk factors for unfavorable seizure outcome in patients with BM and TRE. This might enable to preselect for highly vulnerable patients with postoperative persistent epilepsy who might benefit from accompanying neuro-oncological expertise during further systemical treatment regimes.

\section{Introduction}

Seizures are among the most common symptoms in patients with brain tumors with a consikderable incidence in patients with brain metastases (BM) albeit lower when compared to primary brain tumors [2]. This lower incidence seems to be related to the less infiltrative growth pattern resulting in more circumscribed lesions [9]. Neurosurgical treatment of BM not only reduces the intracranial tumor burden, but also provides excellent seizure control [15].

Nevertheless, some patients with surgically treated BM and tumor-related epilepsy (TRE) with unfavorable seizure outcome embark on further adjuvant therapy, which may itself have an epileptogenic effect [9]. Yet, recurrent seizures have a negative effect on the health-related quality of life (QoL), especially if they are not controlled postoperatively or with long-term medication only [8]. In common treatment settings, patients with primary cancer and newly diagnosed BM are referred back to the primary physician after successful neurosurgical management implementation of systemic treatment of the underlying malignancy. Since these patients with uncontrolled seizures despite surgery might benefit from continuous supportive neuro-oncological expertise accompanying their systemic therapy, their early identification is of crucial importance.

We have therefore reviewed our institutional database for possible preoperatively identifiable risk factors for unfavorable postoperative seizure outcome in patients with newly diagnosed BM and TRE.

\section{Materials And Methods}


We included all BM patients with preoperative TRE and sufficiently documented seizure outcome over 3 months postoperatively that had been surgically treated for BM at the authors' neuro-oncological speciality center between 2013 and 2018. Following the ILAE definition, reported epilepsy was defined as 1) at least 2 unprovoked seizures occurring $>24$ hours apart, or 2) 1 unprovoked seizure and an increased probability of further seizures similar to the general risk of recurrence after 2 unprovoked seizures occurring in the next 10 years [7]. Therefore, patients with BM with both one and/or more than one symptomatic seizure were included in further analysis. Postoperative seizure outcome was evaluated for a period of up to 3 months after surgery to avoid possible interference with a postoperative adjuvant cancer treatment. Pertinent clinical information was collected and entered into a computerized database (SPSS, Version 25, IBM Corp., Armonk, NY). Information recorded included age, sex, initial neurological status according to the Karnofsky Performance Scale (KPS), localization and size of BM, information on multiple BM, seizure status and semiology (focal versus generalized) according to the criteria of the International League Against Epilepsy (ILAE) [14], underlying malignancy, and postoperative seizure outcome.

The indication for surgical treatment of a newly diagnosed intracranial metastasis is given at the weekly tumor board meeting, as previously reported [12].

Postoperative seizure control in terms of ILAE Class I (completely seizure free, no auras) was considered as favorable seizure outcome. An unfavorable outcome was defined as ILAE Class II-VI as previously described [11].

Volumetric analyses of preoperative contrast-enhancing tumor tissue, tumor necrosis and perilesional brain edema were performed manually with commercially available software (TumorTracking Tool, IntelliSpace Portal 5.0, Philips, Best, Netherlands) by two authors (MB, MS). Any discrepancies were resolved in a consensus meeting with the senior author (PS). Therefore, enhancing volume on postcontrast $\mathrm{T} 1$ including central necrosis was considered as tumor. A non-enhancing region within the tumor on post-contrast T1 was determined as necrosis. The volume on T2/FLAIR hyperintensities surrounding the lesion, excluding the tumor volume, was classified as perilesional edema (Figure 1). Two ratios were then calculated to better depict distinct aspects of each BM compartment: 1) necrosis/tumor-ratio (NTR; necrosis divided by tumor volume), and 2) edema/tumor-ratio (ETR; edema divided by tumor volume), as as previously described by Henker et al. [5] (Figure 1).

The study was approved by the local ethics committee. Because this study does not imply any burden for the patients and all data were retrieved from existing databases and registries, no informed consent had to be sought

\section{Statistical analysis}

Data analyses were performed using the SPSS computer software package (version 25, IBM Corp., Armonk, NY). Categorical variables were analyzed in contingency tables using the Fisher's exact test. The Mann-Whitney U-test was chosen to compare continuous variables as data were mostly not normally 
distributed. The area under the curve (AUC), as well as specificity and sensitivity were determined using receiver operating characteristic (ROC) curves to identify a cut-off value of NTR for prediction of postoperative seizure outcome in the current patient population. Results with $p<0.05$ were considered statistically significant.

\section{Results}

\section{Patient characteristics and seizure outcome}

We identified 38 patients with preoperative TRE who had undergone surgical treatment of BM at the authors' institution between 2013 and 2018 . Overall, 34 patients (90\%) achieved favorable postoperative seizure outcome. Patients with unfavourable seizure outcome more frequently had generalized seizures and a shorter OS. However, differences between patients with favourable and unfavourable seizure outcome did not reach statistical significance (Table 1).

\section{Analysis of imaging characteristics and postoperative seizure outcome}

Temporal localization of surgically treated BM or hemorrhagic transformation did not significantly affect postoperative seizure outcome $(p=1.0)$ (Table 2). While multiple BM at the time of surgical treatment were more frequent among patients with an unfavourable seizure outcome, this difference did not reach statistical significance $(p=0.19)$.

Patients with an unfavourable seizure outcome presented with a significantly larger tumor volume compared to patients with favorable seizure outcome (median volume: $3.1 \mathrm{cc}$ versus $0.2 \mathrm{cc} ; \mathrm{p}=0.002$ ). Furthermore, an initial midline shift of $\geq 7 \mathrm{~mm}$ showed a significant association with unfavorable postoperative seizure outcome compared to patients with a preoperative midline shift of $<7 \mathrm{~mm}(50 \% \mathrm{vs}$. $3 \% ; p=0.025$ ) (Table 2).

The ROC analysis revealed a NTR cut-off value of 0.2 regarding the predictability of postoperative seizure-freedom ( $A U C=0.81, S E=0.14, p=0.046$; sensitivity $75 \%$, specificity $65 \%)$. Subsequently, a NTR of > 0.2 was found to be significantly associated with unfavorable postoperative seizure outcome in further volumetric analysis ( $\mathrm{p}=0.047, \mathrm{OR} 16,95 \% \mathrm{Cl} 1.4-180.9)$ (Table 2 ).

\section{Discussion}

Current evidence estimates that in about $4 \%$ of patients with epilepsy, the cause is the presence of a brain tumor. In contrast, the incidence of epilepsy in patients with brain tumor is about $30 \%$ [7]. However, seizure prevalence in brain tumors follows an inverse relationship related to tumor growth rate and associated malignancy [6]. Nevertheless, tumor-related epilepsy (whether due to primary brain tumor or BM) can massively reduce HRQoL in affected patients [9,7]. We found that neurosurgical treatment of BM could achieve postoperative seizure freedom in the majority of patients. This finding is in line with previous work $[9,4]$. Patients with BM due to underlying melanoma or lung cancer exhibit the most 
frequent incidence of TRE among patients with BM $[9,13]$. In the present study, no association was apparent between underlying cancer type and the preferential development of preoperative epilepsy in patients with BM. This may be due to patient selection, as the present data focused solely on patients with BM requiring surgery. Furthermore, the present study highlights preoperative imaging features associated with an unfavorable postoperative seizure outcome.

A preoperative midline shift of $7 \mathrm{~mm}$ or more was associated with an unfavorable postoperative seizure outcome. It is most likely a surrogate parameter for a significant space-occupying effects of the respective metastasis, whether it is tumor- or edema-related. The extent of peritumoral edema is known to be an independent predictor of postoperative seizure outcome from experience in other diseases [11]. In addition to the space-occupying component of edema and accompanying irritation of the surrounding parenchyma, a decrease in inhibitory neurotransmission in the peri-tumoral tissue (with or without edema) has also been discussed as an underlying explanation for tumor-related epileptogenicity [3]. An alternative mechanism explaining increased midline shift is the BM size as such. The relationship between tumor size and postoperative seizure outcome is well established in other tumor entities (e.g., meningiomas) [11]. Our volumetric data indicate a significantly larger volume of the metastatic lesions in patients with poor postoperative seizure outcome compared with BM patients with TRE and postoperative seizure freedom.

In addition to the BM volume, the ratio of intratumoral necrosis volume to total tumor volume was demonstrated to be significantly associated with postoperative seizure outcome in patients with BM and TRE. On the basis of the present data, we were able to establish a correlation between a necrosis/tumor volume ratio $>0.2$ and an unfavorable seizure outcome. The cause of necrosis formation in BM and its mechanistic relationship to poor clinical outcome remain largely unknown [10]. A common hypothesis for the development of tumor necrosis is that the rapid growth of malignant cells outgrows the capacity of inherent blood supply, generating hypoxic conditions resulting in necrotic tissue areas [1]. Immunologic factors, such as the causal role of cells of the innate and adaptive immune systems in necrosis formation, have also been considered [1]. These explanatory attempts suggest an even more massive intratumoral remodeling process in the case of increased necrosis formation in BM. The associated metabolic products, as well as immunological processes, could provide the explanation for the fact that now, for the first time, a correlation between the necrosis-tumor ratio and the postoperative seizure outcome in BM patients has been successfully established in the present study.

\section{Limitations}

The present study has several limitations. As with all retrospective studies, limitations of our study are inherent in the design and include retrospective data collection. Furthermore, there is only a small number of patients with postoperative unfavourable seizure outcome in our cohort. In addition, follow-up time of postoperative seizure assessment was only 3 months. We cannot rule out that many of the patients were preoperatively treated with steroids, which could be a confounding factor in this study that affects peritumoral edema volume and subsequently the volumetric analysis. 


\section{Conclusions}

Neurosurgical resection of BM is highly effective in the treatment of tumor-associated epilepsy.

Additionally, the present study shows that preoperative higher tumor volumes, a midline shift $>7 \mathrm{~mm}$ and a necrosis/tumor volume ratio $>0.2$ are associated with postoperative unfavorable seizure outcome in patients with BM and TRE. These variables might enable to preoperatively identify the subset of BM patients that are at high risk of postoperative unfavourable seizure outcome and might therefore benefit from accompanying neuro-oncological expertise during further systemical treatment regimes.

Further longitudinal studies in larger patient cohorts are needed to confirm our results and assess how a neuro-oncological binding could improve seizure-control and subsequently the QoL in patients with BM and TRE.

\section{Declarations}

\section{Ethics Approval}

The study was approved by the local ethics committee at the University Hospital Bonn.

\section{Conflict of Interest}

The authors declare that the article content was composed in the absence of any commercial or financial relationship that could be construed as a potential conflict of interest.

\section{Funding}

The present research received no funding.

\section{Availability of Data and Material}

All data generated or analysed during this study are included in this published article.

\section{Code Availability}

'Not applicable'

\section{Consent to participate}

Informed consent was not sought as a retrospective study design was used.

\section{Consent for publication}

All authors agreed to the publication of the manuscript.

\section{Author Contributions}


Conceptualization, M.B., M.S. and P.S.; data curation, M.B., M.S., M.H., A.-L.P. and P.S.; formal analysis, M.B., M.S., A.-L.P., and P.S.; writing-original draft preparation, M.B., M.S. and P.S.; writing-review and editing, M.B., M.S., M.H., C.B., V.B., L.E., A.-L.P., E.G., M.H., Y.-D.K., F.L., A.R., C.S., R.S., J.W., U.H., H.V., N.S. and P.S.; visualization, M.B., M.S., A.-L.P. and P.S.; supervision, M.S. and P.S.

All authors have read and agreed to the published version of the manuscript.

\section{References}

1. Atanasov G, Schierle K, Hau HM, Dietel C, Krenzien F, Brandl A, Wiltberger G, Englisch JP, Robson SC, Reutzel-Selke A, Pascher A, Jonas S, Pratschke J, Benzing C, Schmelzle M (2017) Prognostic Significance of Tumor Necrosis in Hilar Cholangiocarcinoma. Ann Surg Oncol 24:518-525. doi:10.1245/s10434-016-5472-0

2. Chan V, Sahgal A, Egeto P, Schweizer T, Das S (2017) Incidence of seizure in adult patients with intracranial metastatic disease. J Neurooncol 131:619-624. doi:10.1007/s11060-016-2335-2

3. Chen DY, Chen CC, Crawford JR, Wang SG (2018) Tumor-related epilepsy: epidemiology, pathogenesis and management. J Neurooncol 139:13-21. doi:10.1007/s11060-018-2862-0

4. Grewal J, Grewal HK, Forman AD (2008) Seizures and epilepsy in cancer: etiologies, evaluation, and management. Curr Oncol Rep 10:63-71. doi:10.1007/s11912-008-0010-2

5. Henker C, Kriesen T, Scherer M, Glass A, von Deimling A, Bendszus M, Weber MA, Herold-Mende C, Unterberg A, Piek J (2019) Association Between Tumor Compartment Volumes, the Incidence of Pretreatment Seizures, and Statin-Mediated Protective Effects in Glioblastoma. Neurosurgery 85:E722-E729. doi:10.1093/neuros/nyz079

6. Hildebrand J, Lecaille C, Perennes J, Delattre JY (2005) Epileptic seizures during follow-up of patients treated for primary brain tumors. Neurology 65:212-215. doi:10.1212/01.wnl.0000168903.09277.8f

7. Kim YZ, Lee EH, Lee KS (2011) Clinical Analysis for Brain Tumor-Related Epilepsy during Chemotherapy for Systemic Cancer with Single Brain Metastasis. Cancer Res Treat 43:160-169. doi:10.4143/crt.2011.43.3.160

8. Lee SA, Kim MJ, Lee HW, Heo K, Shin DJ, Song HK, Kim OJ, Kim SO, Lee BI (2015) The effect of recurrent seizures on cognitive, behavioral, and quality-of-life outcomes after 12 months of monotherapy in adults with newly diagnosed or previously untreated partial epilepsy. Epilepsy Behav 53:202-208. doi:10.1016/j.yebeh.2015.10.020

9. Ruda R, Mo F, Pellerino A (2020) Epilepsy in brain metastasis: an emerging entity. Curr Treat Options Neurol 22:6. doi:10.1007/s11940-020-0613-y

10. Sambade MJ, Prince G, Deal AM, Trembath D, McKee M, Garrett A, Keith K, Ramirez J, Midkiff B, Blackwell K, Sammons S, Leone JP, Brufsky A, Morikawa A, Brogi E, Seidman A, Ewend M, Carey LA, Moschos SJ, Hamilton RL, Vincent B, Anders C (2019) Examination and prognostic implications of 
the unique microenvironment of breast cancer brain metastases. Breast Cancer Res Treat 176:321328. doi:10.1007/s10549-019-05211-1

11. Schneider M, Güresir Á, Borger V, Hamed M, Racz A, Vatter H, Güresir E, Schuss P (2019) Preoperative tumor-associated epilepsy in patients with supratentorial meningioma: factors influencing seizure outcome after meningioma surgery. Journal of neurosurgery:1-7. doi:10.3171/2019.7.JNS19455

12. Schneider M, Heimann M, Schaub C, Eichhorn L, Potthoff AL, Giordano FA, Güresir E, Ko YD, Landsberg J, Lehmann F, Radbruch A, Schwab KS, Weinhold L, Weller J, Wispel C, Herrlinger U, Vatter H, Schäfer N, Schuss P (2020) Comorbidity Burden and Presence of Multiple Intracranial Lesions Are Associated with Adverse Events after Surgical Treatment of Patients with Brain Metastases. Cancers 12. doi:10.3390/cancers 12113209

13. Urban H, Willems LM, Ronellenfitsch MW, Rosenow F, Steinbach JP, Strzelczyk A (2020) Increased occurrence of status epilepticus in patients with brain metastases and checkpoint inhibition. Oncoimmunology 9:1851517. doi:10.1080/2162402X.2020.1851517

14. Wieser HG, Blume WT, Fish D, Goldensohn E, Hufnagel A, King D, Sperling MR, Luders H, Pedley TA, Commission on Neurosurgery of the International League Against E (2001) ILAE Commission Report. Proposal for a new classification of outcome with respect to epileptic seizures following epilepsy surgery. Epilepsia 42:282-286

15. Wu A, Weingart JD, Gallia GL, Lim M, Brem H, Bettegowda C, Chaichana KL (2017) Risk Factors for Preoperative Seizures and Loss of Seizure Control in Patients Undergoing Surgery for Metastatic Brain Tumors. World Neurosurg 104:120-128. doi:10.1016/j.wneu.2017.05.028

\section{Tables}

Table 1: Patient characteristics 


\begin{tabular}{|c|c|c|c|}
\hline & $\begin{array}{l}\text { Favorable seizure outcome } \\
(n=34)\end{array}$ & $\begin{array}{l}\text { Unfavorable seizure outcome } \\
(n=4)\end{array}$ & \\
\hline $\begin{array}{l}\text { Median age at surgery } \\
\text { (yrs) }\end{array}$ & 61 & 54 & $p=0.37$ \\
\hline female gender & $19(56 \%)$ & $2(50 \%)$ & $p=1.0$ \\
\hline Preoperative KPS $\geq 70$ & $29(85 \%)$ & $3(75 \%)$ & $p=0.51$ \\
\hline \multicolumn{4}{|l|}{$\begin{array}{l}\text { Preoperative seizure } \\
\text { semiology }\end{array}$} \\
\hline \multirow{2}{*}{ partial } & $21(62 \%)$ & $1(25 \%)$ & \\
\hline & $13(38 \%)$ & $3(75 \%)$ & \\
\hline \multicolumn{4}{|l|}{ Primary site of cancer } \\
\hline lung & $13(38 \%)$ & $3(75 \%)$ & $p=0.29$ \\
\hline breast & $5(15 \%)$ & $0(0 \%)$ & $p=1.0$ \\
\hline melanoma & $4(12 \%)$ & $0(0 \%)$ & $p=1.0$ \\
\hline others & $12(35 \%)$ & $1(25 \%)$ & $p=1.0$ \\
\hline Median OS (mo) & $16(95 \%$ Cl 2.0-30.0) & 8 (95\% Cl 2.1-13.9) & $p=0.28$ \\
\hline
\end{tabular}

yrs, years; KPS, Karnofsky Performance Scale; OS, overall survival; mo, months.

Table 2: Imaging-based analysis for factors influencing seizure outcome

\begin{tabular}{|llll|}
\hline & $\begin{array}{l}\text { Favorable seizure } \\
\text { outcome }(\mathbf{n = 3 4})\end{array}$ & $\begin{array}{l}\text { Unfavorable seizure } \\
\text { outcome }(\mathbf{n}=4)\end{array}$ & \\
\hline $\begin{array}{l}\text { temporal location of } \\
\text { BM }\end{array}$ & $6(18 \%)$ & $1(25 \%)$ & $\mathrm{p}=1.0$ \\
\hline $\begin{array}{l}\text { multiple BM } \\
\begin{array}{l}\text { hemorrhagic } \\
\text { transformation }\end{array}\end{array}$ & $6(18 \%)$ & $2(50 \%)$ & $\mathrm{p}=0.19$ \\
\hline $\begin{array}{l}\text { preoperative midline } \\
\text { shift } \geq 7 \text { mm }\end{array}$ & $1(3 \%)$ & $1(25 \%)$ & $\mathrm{p}=1.0$ \\
\hline $\begin{array}{l}\text { median tumor volume } \\
\text { (cc) }\end{array}$ & 0.2 & $2(50 \%)$ & $\mathrm{p}=0.025,0 \mathrm{OR} 33,95 \%$ \\
\hline NTR $>0.2$ & $2(6 \%)$ & 3.1 & $\mathrm{Cl} 2.0-538.7$ \\
\hline
\end{tabular}

$\mathrm{BM}$, brain metastasis; $\mathrm{cc}, \mathrm{cm}^{3}$; NTR, necrosis/tumor-ratio 
Figures
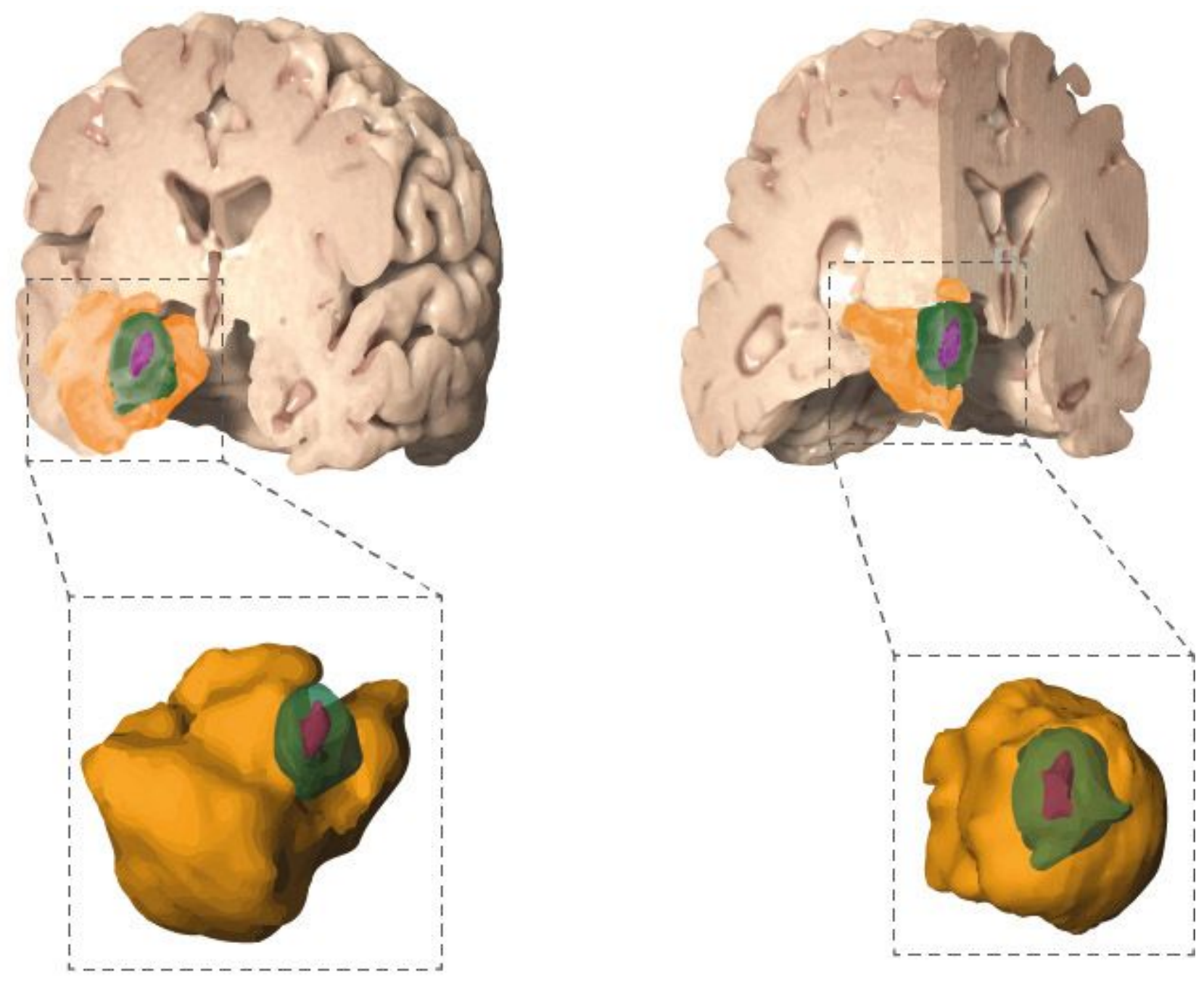

\section{Edema}

Tumor

Necrosis

Figure 1

Illustration of metastatic tumor-, necrosis- and tumor-related edema-volumes; right: frontal view; left: frontotemporal view 